\title{
THE LIBRARY QUARTERLY
}

Volume 82

January 2012

Number 1

\section{AN INTEGRATED CUSTOMER KNOWLEDGE MANAGEMENT FRAMEWORK FOR ACADEMIC LIBRARIES ${ }^{1}$}

\author{
Farhad Daneshgar² and Mehri Parirokh ${ }^{3}$
}

The ability of academic libraries to produce timely and effective responses to various environmental changes constitutes a major challenge for them to enhance their survival rate and maintain growth in competitive environments. This article provides a conceptual model as an analytical tool for both improving current services as well as creating innovative services through appropriate management of client knowledge in academic libraries. Through an exploratory qualitative case study and from reviewing the current literature in knowledge management, a theoretical framework is proposed for managing customer knowledge. The proposed framework is expected to improve existing library services and create new innovative services in academic libraries.

\section{Background}

According to a survey reported by Reid G. Smith and Adam Farquhar, customer knowledge was quoted as the most important type of knowledge (97 percent) in order for organizations to act effectively. In the survey, this was followed in importance by knowledge about best practices and effective processes (87 percent) and knowledge about competencies and capabilities

1. This research has been supported by the John Metcalfe Memorial Fund at the School of Information Systems, Technology, and Management, University of New South Wales, Australia. Thanks also to Fletcher Cole for his editorial suggestions and to the referees for their comments.

2. Visiting fellow, Bangkok University, Thailand, and senior lecturer, Australian School of Business, University of New South Wales, Australia; Telephone +61-2-9385 4241; E-mail f.daneshgar@unsw.edu.au.

3. Associate professor of information and library science, Ferdowsi University of Mashhad, Iran; E-mail parirokh@ferdowsi.um.ac.ir.

[Library Quarterly, vol. 82, no. 1, pp. 7-28]

(C) 2012 by The University of Chicago. All rights reserved.

0024-2519/2012/8201-0002\$10.00 
(86 percent) [1]. Managing customer knowledge is particularly critical to today's academic libraries, which are characterized by strong service orientation and operate in knowledge economies with rapidly changing user requirements [2]. Academic libraries are knowledge-creation enterprises in which a large amount of knowledge is created regularly for their customers or library users with rapidly evolving needs and service requirements. Through interfacing with their clients, librarians respond to the emerging informational and service requirements of their clients. Sophisticated systems have already been developed for librarians to solicit, track, understand, and act on users' opinions of service quality. For example, the Association of Research Libraries (ARL) has developed a suite of programs called LibQUAL + that provides a web-based survey bundled with training that helps libraries assess and improve library services, change organizational culture, and market the library [3]. We believe that our findings will provide useful theoretical and conceptual grounds for the systems such as LibQUAL + to extend their functionality to explicitly incorporate the additional types of customer knowledge that have been identified in this article.

From the knowledge management (KM) perspective, the role of libraries has been emphasized as a facilitator of various knowledge processes such as generation, sharing, dissemination, and evaluation of knowledge. This is also the main perspective in the current study and will be discussed in detail later.

Many successful organizations have already put considerable effort into acquiring knowledge from their customers. KM systems have been developed to integrate the knowledge of their employees and customers [4]. It has been suggested that the major challenge of managing knowledge is less in its creation and more in its capture and integration $[5,6]$.

For the further development of KM systems in academic libraries, it is essential to define the specific forms of the various knowledge activities, such as capturing and exploiting knowledge, that pertain there. We argue that when defining these knowledge activities, knowledge and expertise that reside in librarians as well as their clients must be taken into consideration.

\section{Motivation and Aims of the Study}

Through the routine use of sophisticated information and communication technologies (ICT), academic libraries have accumulated vast amounts of data from their clients. These come in various forms: interview scripts, database records of customer transactions, recorded items stored in various media, and undocumented but valuable experience and knowledge gained 
by librarians over time. The availability of such a body of data and the willingness of the case study library to participate in research collaboration motivated us to initiate the current investigation.

The case study organization, called LIBRARY, has among its goals the transformation of the library into a modern service-oriented organization that (i) generates timely and effective responses to unpredictable needs of its clients and other environmental factors and (ii) provides innovative services to its clients. This gives rise to the motivating research question in this study, which will be explored later: How can the existing bulk of customer knowledge accumulated in many of today's academic libraries be used in more effective ways? In the next section, the literature on customer KM will be reviewed. This is followed by a presentation of the case study organization, a discussion of the research methodology, an analysis of results, a conclusion, and an outline of future work.

\section{Customer Knowledge Management}

The three major groups of clients of academic libraries-undergraduate students, postgraduate students, and academics-generally have high expectations of the services offered by the library $[2,7,8]$. This requires librarians to possess an appropriate knowledge of their expectations, sometimes indirectly, through customer feedback, suggestions, casual remarks, news from various faculty meetings, as well as wider commercial and industry knowledge.

In the field of KM, the significant role of customers in generating ideas has already been recognized (e.g., [9-11]). In knowledge economies, customers do not simply make up a passive audience but rather are active knowledge partners. Customer input about the context and perception of services is valuable to organizations, and yet only a few organizations actually manage well "their perhaps most precious resource: their clients' knowledge" [11, p. 459]. We believe that despite considerable efforts in libraries to manage information from their clients (e.g., [3]), a lack of "market-orientation" focus and associated research perspective may be one of the reasons for underutilization of various types of the customers' knowledge in many of today's organizations, including the academic libraries. This study adopts a market-orientation approach to partially fill the current gap in the literature. The concept of "market orientation" is closely linked to the organizational learning processes and refers to the organizationwide generation of knowledge about current and future customer needs, the dissemination of knowledge across departments, and organization-wide responsiveness [12]. Our research involved academics from various schools and faculties within the case study university. We looked at the dissemi- 
nation of knowledge across schools and the library's responsiveness to both the current and the future needs of academics in relation to potentially innovative library services.

\section{Definition of Customer Knowledge}

From an organizational perspective, customers' knowledge can be categorized into at least the following three classes.

Knowledge about Customers (KAC).-The goal of collecting this kind of knowledge is to understand customers' motivations and to address them in a personalized way. This category deals with factual information about clients (e.g., gender, educational background, research areas) as well as information needs and interests, as explained by the customers themselves [13]. Examples of this knowledge include "certain academic member needs to order a specific journal article" or "an undergraduate student is spending the next two semesters in another university as an exchange student and would require more specialised library services" [13, p. 43]. This type of knowledge is normally explicit and therefore can be codified. One major method for collecting knowledge about the academic members is by faceto-face interviews with academics on a regular basis (see the appendix for samples of such reports). As well, since librarians are in constant interaction with their clients, indirect or tacit knowledge about client behavior and needs is included in this category.

Knowledge from Customers (KRC).-This category deals with the clients' perceptions, insights, reactions, knowledge about other products, suppliers, markets, suggestions, and overall knowledge of the competitive environment [13, p. 111]. Examples include experience with Google, comments about existing services provided by the library, and clients' expectations about existing and future services. This category of customer knowledge aims to facilitate continuous improvement, for example, through service improvements or new product developments. It provides a view of how the customers perceive their environment and their particular role within that environment. This is seen to provide the library with a context for the creation and delivery of services.

Knowledge for Customers (KFC).-This category of customer knowledge is generated by KAC and KRC. The current study proposes a theoretical framework for integrating $\mathrm{KAC}$ and $\mathrm{KRC}$ in order to produce $\mathrm{KFC}$. Although all service-based enterprises, including libraries, provide various services to their customers, the logical relationship between different kinds of customers' knowledge is often missing, and we believe that this study fills the existing gap. 


\section{Customer Knowledge Management Systems}

These are systems for enacting various customer knowledge management (CKM) activities and relevant controls with the aim of organizing customer knowledge. A customer knowledge management system (CKMS) consists of at least three elements:

1. An information management component, such as a content management subsystem for coding and organizing information sources and repositories $[5,14,15]$.

2. An information technology component, such as an Intranet, e-mail system, database management system, web log, website, alerting system, bulletin board, chat facilities, and so on. The information-technology component facilitates knowledge acquisition, organization, access, and dissemination [13, p. 219].

3. Strategies, procedures, and policies for creating a "balance between innovation and organizational structure" $[13$, p. 44] and about the appropriateness of CKM activities, such as the acquisition, creation, integration, and usage of knowledge.

The aim of CKMS is to ensure (i) the selection of appropriate knowledge, (ii) the proper building of knowledge repositories, (iii) the workability of the process of managing the knowledge, and (iv) the integration of all knowledge and the application of results in the creation of new knowledge and services crucial for an organization's stability and development [16$18]$.

\section{Customer Knowledge Management Models}

Several CKM frameworks already exist in the current KM literature for the representation and implementation of CKM systems. Henning Gebert, Malte Geib, Lutz Kolbe, and Walter Brenner proposed a CKM model for achieving four fundamental goals: (i) knowledge transparency; (ii) knowledge dissemination, as related to the degree and intensity of knowledge distribution; (iii) knowledge development, based on the degree of knowledge adaptation and creation; and (iv) knowledge efficiency [19]. This model focuses on the selection of crucial customer knowledge from among various available kinds of knowledge.

Ranjit Bose and Vijaya Sugumaran [5] propose a CKM that is an integrated $\mathrm{KM}$ and customer relationship management model that also includes a knowledge-learning loop. The components of this model are informationtechnology-based collaborative components, information management tools, and processes for capturing, managing, creating, disseminating, and sharing knowledge. 


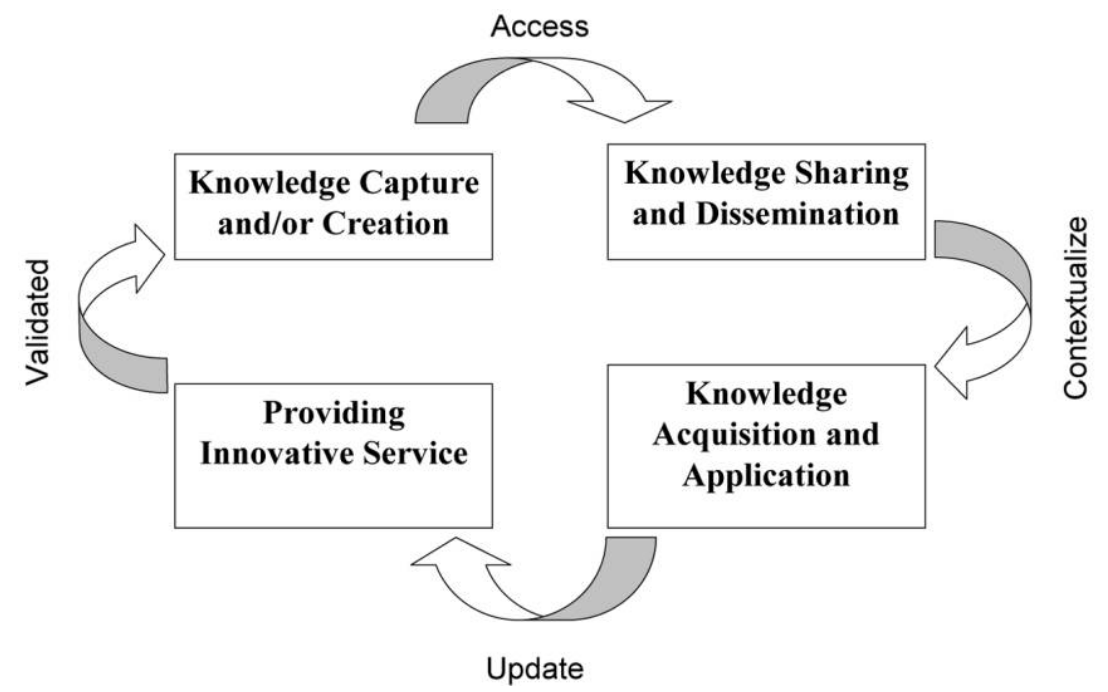

FIG. 1.-Integrated Customer Knowledge Management Model

An important model for the study reported in this article is provided by Kimiz Dalkir [13, p. 43], who developed an integrated generic model for the knowledge cycle consisting of three stages: (i) knowledge capture or creation, (ii) knowledge sharing and dissemination, and (iii) knowledge acquisition and application, as shown in figure 1.

Various activities are performed in relation to customers' knowledge, each resulting in a different knowledge transformation. Starting from knowledge capture or creation, KAC and KFC are captured either directly or indirectly (e.g., through face-to-face contacts, data mining, and knowledge discovery methods). The captured knowledge is then accessed and shared by the librarians in order to be contextualized and used for enhancing existing services and developing new ones. Knowledge utilization by customers creates customer feedback, which can be used for evaluation of these services. Results of this evaluation, together with customers' new knowledge about updated services, are then captured, and the cycle continues.

Description of the Case Organization: The LIBRARY

The case study organization under investigation (the LIBRARY) is an academic library in an Australian university with a strong research culture. 
In 2009, the university had 40,000 students, including more than 7,000 international students from over 130 different countries. During the last decade, the university has been ranked consistently in the top fifty by the United Kingdom's Times Higher Education Supplement (http://www.times highereducation.co.uk/).

The LIBRARY is structured into three departments, each headed by a director who reports to the university librarian: The Information Resources Department acquires, processes, and manages the collections held by the library. The negotiation of terms from vendors and the management of the collection budget are also included in this portfolio. The Infrastructure Department is responsible for library facilities, including opening hours, circulation, library information technology, human resources, and finance, and is headed up by the deputy university librarian. And the Information Services Department (ISD) has the responsibility for the delivery of professional services to the university community. This includes service development and delivery and relationships with the teaching and research faculty and the university-wide community. The ISD is responsible for the development and delivery of services that allow library users (the "customers" of this study) to reach their academic goals. The ISD is the main focus of this study.

Recently, the ISD has moved to an integrated model of teams belonging to the following three service units: Service Innovation aims to keep abreast of international best practices and developments in technology to ensure that the library services are efficient and appropriate. This unit is responsible for the definition of services and the development and management of measures to enable the library to determine what services are being used and what outcomes are being achieved. In addition, the unit receives feedback from customers, including various university communities, which may lead to services being modified or upgraded. This feedback comes from a variety of areas but primarily through the Outreach Team and faculty meetings as shown in figure 2.

Service Development is for the development and maintenance of all new services such as ELISE (Enabling Library and Information Skills for Everyone), online tutorials, subject guides, and so on. It receives service definitions from the Services Innovation Unit, and on the basis of this input, existing services are modified, or new ones are created. In addition, this unit manages the library's online presence, and creates standardized templates for service delivery.

The Academic Services Unit is for building relationships with faculty and identifying, promoting, and delivering services for them. Either through discussion with the community (Outreach Team) or from the delivery of services (Services Team), customer feedback is given to the Service Innovation Unit for consideration. Each faculty within the university has been 


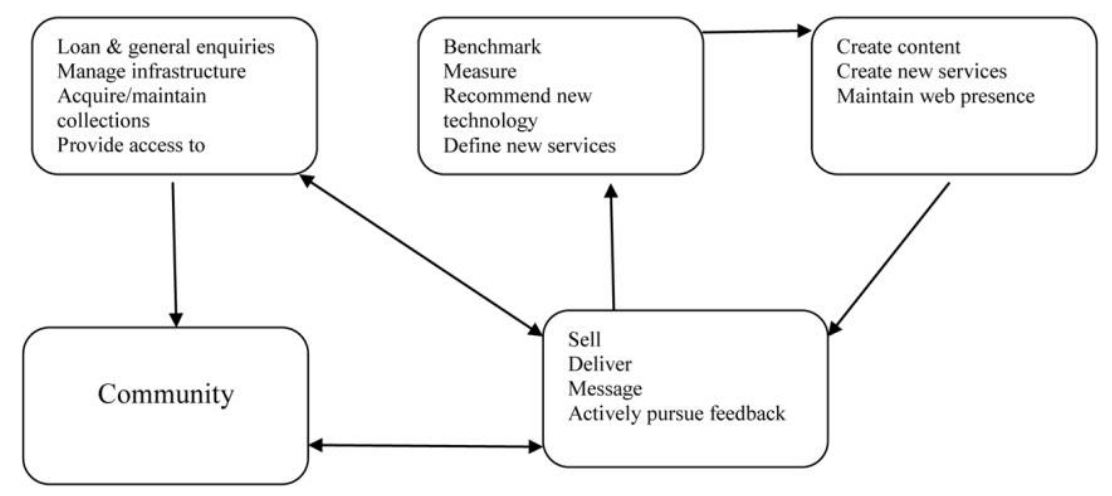

FIG. 2.-Knowledge cycle diagram in Information Services Department in LIBRARY.

assigned specialist contact librarians who are available to provide information, organize service delivery, give seminars, listen to concerns, facilitate feedback, and work through any issues that may exist in relation to the library. Figure 2 demonstrates a knowledge-flow perspective for the ISD. During the past five years, a vast amount of knowledge relating to the LIBRARY's customers has been recorded by the LIBRARY, and its management is now exploring more creative methods for organizing this knowledge, hence, this study.

\section{Research Methodology}

As briefly mentioned, the overarching question for the study was, How can the existing bulk of customer knowledge accumulated in many of today's academic libraries be used in more effective ways? This question was split further into the following questions:

1. How can the existing bulk of customers' knowledge available in academic libraries be organized?

2. How can this knowledge be used effectively?

3. How can the benefits of CKM in academic libraries be evaluated?

The research methodology adopted for answering the above questions was a combination of literature review and case study. One major reason for selecting the LIBRARY as the case study of the current study was a move by the LIBRARY toward a strong service orientation and an explicit com- 
mitment to satisfying its customers' continuously changing needs. Another reason was the presence of a large number of interviews with 2,500 academic staff from which the management was willing to explore valuable knowledge about its customers.

The steps taken in the study were:

1. Literature in related fields was reviewed in order to determine current available methods for effectively organizing the customers' knowledge.

2. On the basis of this review, a knowledge taxonomy was adopted for organizing customers' knowledge in academic libraries [20].

3 . The next step was to find a theoretical model for representing various activities in the CKM cycle. By synthesizing the existing CKM models as well as close consultations with the LIBRARY staff, an appropriate specialized CKM model was developed for the LIBRARY. This model will constitute the main analytical tool for any future development of a CKM system for the LIBRARY. Development of a full-blown computerized CKM is the subject of a future study, and this study mainly focuses on the conceptual design of the CKM.

4. Another input into the study was the adoption of a taxonomy of customer knowledge and the building of a knowledge base using the Leximancer software (https://www.leximancer.com/).

5. Finally, the effectiveness of the model and a partially developed system was evaluated.

\section{An Integrated CKM Model for LIBRARY}

Generally speaking, the customers of the LIBRARY are either students or academic members (faculty), and the feedback generated by these groups during their various interactions can be valuable. Faculty not only provide feedback about the library services that are specific to them, but they can also provide it regarding the services for students. For this reason, the current study has mainly focused on the knowledge about, from, and for faculty. By combining the knowledge cycle model of figure 1 with the three categories of customer knowledge in libraries, an initial version of a CKM conceptual model for libraries was developed as shown in figure 3.

According to this model, librarians collect information "about" and "from" their faculty customers, particularly during interviews (also referred to as outreach librarian interviews with academics, as shown in the appendix). The captured customer knowledge is then shared and disseminated among librarians and library decision makers so that it can be correctly understood and interpreted. It needs to be "applied" to the current services 


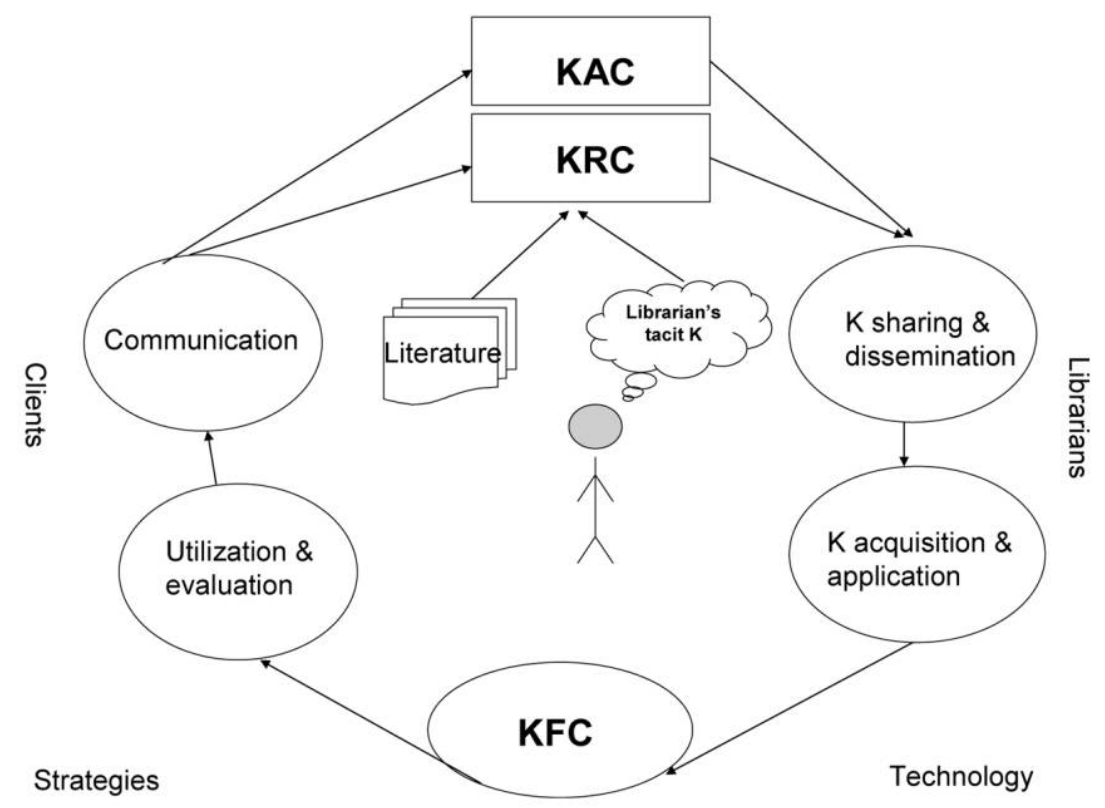

FIG. 3.-Initial integrated Customer Knowledge Management Model; KAC = knowledge about customers; $\mathrm{KRC}=$ knowledge from customers; $\mathrm{KFC}=$ knowledge for customers.

so that appropriate new/updated services can be created and enabled by ICT (usually). The knowledge is then made available to customers for their "utilization." This generates new customer feedback, which in turn will be used by the librarians for the "evaluation" of library services. Results of this evaluation together with the customers' feedback are then used as new KAC and KRC, and the cycle continues.

The first stage in organizing customer knowledge is the adoption of a categorization scheme in the form of a customer knowledge taxonomy. The aim of the taxonomy is to provide a formal and explicit specification of a shared conceptualization of customer knowledge, which among other things, will circumvent the problems created by the multiple knowledge maps that the librarians will have. The formation of subjective knowledge maps is said to be the result of variations in the perspective and understanding of knowledge workers' knowledge of their customers [18]. The adopted taxonomy [20] also plays a major role in storing and accessing large amounts of customer-related information that are created as a result of both availability of advanced information and communication techno- 


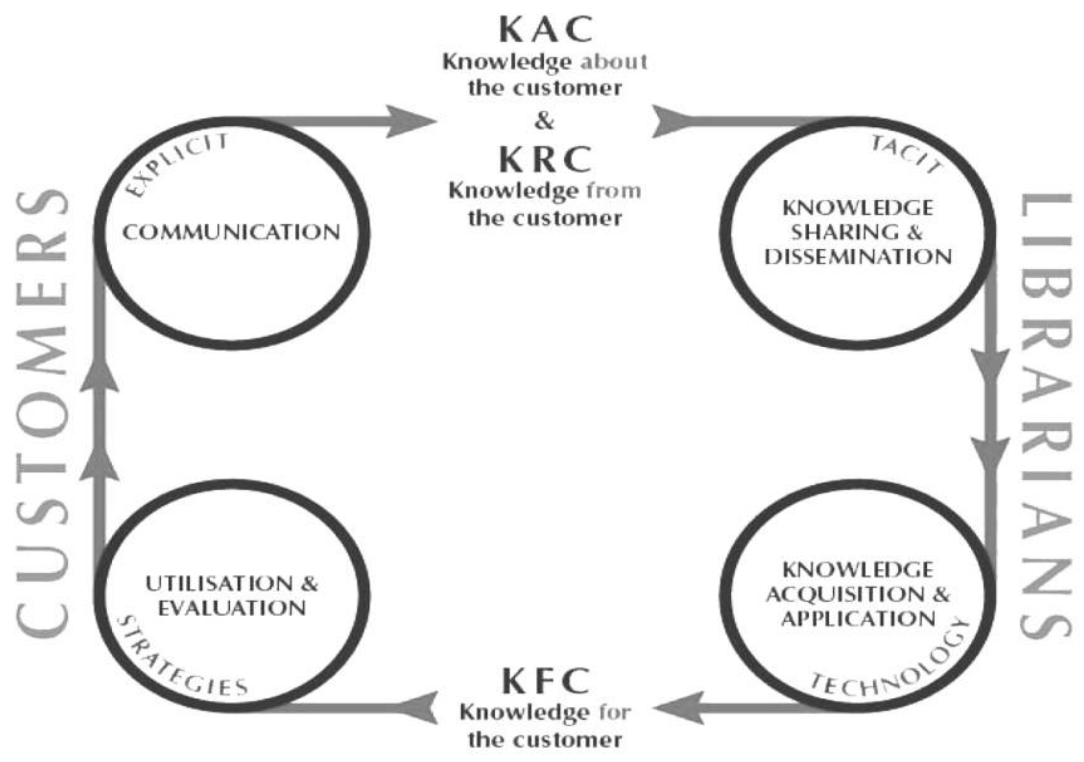

FIG. 4.-Final version of an integrated knowledge flow diagram for customer knowledge in LIBRARY.

logical infrastructures as well as various emerging processes and related transactions in today's increasingly complex academic libraries. Finally, it can potentially provide a "consistent and coherent conceptualization that is extensible and easily reusable in similar environments" [21, pp. 28-30].

The initial CKM model of figure 3 was shown to the ISD manager of the LIBRARY for further validation and refinement based on best practices. This procedure was accomplished over two intensive interview sessions corresponding to the following stages.

In a series of two interviews, the theoretical model of figure 3 was explained to the ISD director, with ample opportunities for questions and clarifications. After making sure that the theoretical model was fully understood, the director was asked to prepare a comprehensive set of comments on the suitability of the initial version of the theoretical model of figure 3 for the LIBRARY. We were able to draw on the director's and manager's knowledge of the ISD's objectives and the large body of customer data.

In a subsequent meeting, the ISD director presented us with a modified version of the initial model in figure 3 , which is shown in figure 4 . Despite similarities between the two models in figures 3 and 4, this was felt to 
reflect the LIBRARY's business strategy more accurately. After further discussion, we and the ISD manager agreed on the final version of the CKM model as shown in figure 4 , which is the main contribution of the current study. One major modification to figure 3 was the renaming of the knowledge capture phase as the communication phase. Another modification was explicit incorporation of the term "technology" as the major enabler of the knowledge acquisition and application phase, as well as explicit incorporation of the term "strategies" as the major directive for knowledge utilization and evaluation.

\section{The Communication (Knowledge Capture or Creation) Phase}

The most commonly used methods for capturing KAC and KRC in the LIBRARY were combinations of direct interviews with customers, surveys, and data mining. The KFC, however, was derived knowledge and created by combining the other two knowledge categories, as shown in figure 4 . The methodology for integration of KAC and KRC can be summarized in the following three steps:

Step 1: The "tacit" (generally understood, taken for granted) component of the librarians' knowledge that was initially documented as a result of interfaces with their customers (i.e., KAC $+\mathrm{KRC}$ ) was evaluated by (i) using the existing body of knowledge derived from the literature and (ii) sharing and refining this tacit component with other librarians with similar experiences.

Step 2: Both KAC and KRC were shared among the ISD librarians.

Step 3: The new understanding created during this knowledge acquisition and application phase led to new ideas being used for designing services for customers, on the basis of the third category of customer knowledge, that is, KFC.

The current study not only develops a specialized version of Henning Gebert et al.'s [22] generic CKM model, it also makes a practical distinction between tacit and explicit knowledge for all three categories of customer knowledge, in order to facilitate the effective management of it. One reason for making such a distinction is that the current state of technology provides rather different types of technological solutions for supporting these different types of knowledge in an organization. 
Development and Evaluation of the Customers' Knowledge Base (CKB)

To provide a final design directive for a future full-blown implementation of CKMS, the following development methodology was applied to the LIBRARY for the development and evaluation of the proposed CKB that initially stores massive available customer data in the LIBRARY. This CKB will constitute a major component of any future implementation of CKMS for academic libraries. The three steps of the methodology are the following three sections.

\section{Knowledge Discovery Process}

The aim here was to derive various categories of customer knowledge from the existing bulk of data from 2,500 semistructured interviews with faculty. Each interview normally took between sixty and ninety minutes, from which a "customer call report" was generated (see the appendix). The ultimate goal of this step was to store and be able to access all available data on call reports classified in various knowledge types. The data in the call reports needed additional transformation for us to discover the various relevant knowledge chunks from the available interview scripts.

A focus group was then formed to develop a uniform coding scheme for categories of customer knowledge. The participants in this focus group included us, three unit managers within the ISD, and the ISD director. The three unit managers manage different aspects of service development and delivery, which includes the supervision of ten outreach librarians who directly interview the academic members (faculty) of the university.

During a two-hour focus group meeting, one of us played the role of coordinator, and the other played the role of KM expert. The former provided qualitative input to the discussions in order to clarify the points made or to steer the focus of the group in the right direction. Each call report was read aloud by the coordinator, one sentence at a time.

After reading each sentence, and on the basis of the formal definitions of the six categories of customer knowledge (three categories, each category having tacit/explicit subcategories), the unit managers were asked to provide independent feedback in the form of (i) identifying relevant customer knowledge chunks within the sentence that fit the scope and purpose of the study and, (ii) if such relevant knowledge chunks were identified, commenting on the exact category those chunks relate to. After reading each sentence, the feedback was collected by the coordinator and examined. If all three feedback reports were the same, then the categorized data were recorded using the Leximancer software. However, if there were discrepancies and disagreements among the three responses, the matter was discussed until a consensus was reached among all three unit managers. 
Throughout this organizational learning process, the "knowledge management expert" was responsible for handling the latter situation and directing the group toward a consensus. The process continued until all sentences in the call report were read and various knowledge categories were identified. As the last stage, the call report was coded for the future training of the outreach librarians who will themselves go through a similar coding activity after/during any interview they do.

\section{Coding Procedure}

During the above coding exercise, the group was engaged in constant comparative methods suggested by John Levine and Richard Moreland [23]. Chunks of text were compared in order to discover similarities and differences among them. This process highlighted the different properties for each knowledge category and "filled" the category out. Even though the three categories were already decided, they themselves were also constantly compared and contrasted so that those with interrelated themes could be merged under one descriptive overarching category. This process is referred to by Anselm Strauss and Juliet M. Corbin [24] as "selective coding," an integrative process of establishing overarching themes by selecting the "core categories," relating these to other categories, and verifying these relationships. In order to establish the credibility and trustworthiness of the research findings, the use of member checking [25] was employed. This method requires giving the interpretations and conclusions back to the participants and allowing them to react to these initial findings.

\section{Planned Evaluation of the Customer Knowledge Taxonomy}

In future work, the results of the above categorization exercise need to be evaluated for a consistency of conceptualization that is extensible and easily reusable in similar environments. The goal of the evaluation process is to focus on the capacity of the framework to incorporate new meanings, relations, domains, and knowledge over time when the framework is reused in other academic libraries in different institutions. Ideally, this would require longitudinal methods, which were impractical for the short lifecycle of the current research project. A cross-section of existing academic libraries will need to be selected, and views will be sought from the domain expert librarians in this sample about the "correctness" of the categorized results, in the selection of knowledge chunks, in the filling of each category, as well as in the "consistency" of such selection by various coders [21]. As a preliminary test, the theoretical framework was discussed with a chief librarian of a university other than where the LIBRARY was located, with favorable feedback. 
The findings of the current study can be summarized as follows. First, on the basis of the results obtained from the literature, one of the most effective uses of CKM systems is to provide timely and useful knowledge for the customers (KFC). To provide this knowledge, however, it was necessary for the LIBRARY to combine several categories of customer knowledge, both tacit and explicit, as well as the librarians' own expertise. On the basis of these findings, an existing customer knowledge taxonomy was adopted [20] to initially organize the massive bulk of customer data in the LIBRARY, as part of the proposed CKMS.

Second, another major component of the proposed CKMS was an integrated conceptual model synthesized by both reviewing the current literature as well as maintaining close consultations with the LIBRARY staff. The proposed conceptual model was validated both syntactically and semantically through an expert panel as well as by the librarians themselves. The method applied for such syntactic and semantic validity was the semiotic conceptual model quality framework (CMQF) [26]. The "expert panel" included the following individuals: (i) the second author, who is an associate professor and the librarian of a large university in the Middle East and was invited to the authorship group as a result of valuable efforts that she contributed to this and subsequent research activities of the article; (ii) a professor of library studies at the same university who was visiting the case study university at the time; and (iii) the library services manager at an Australian university.

Third, the CKMS model was then applied to interview data. The main promise of the CKMS is that it facilitated creation of new knowledge necessary for understanding customers' information needs and interests, leading to innovative ideas and new services for the library.

Finally, the practical benefits of the above findings to academic libraries are manifold. The study has highlighted the enormous amount of tacit knowledge that librarians possess in relation to their customers; knowledge that can now be organized and systematically accessed. Before this study, no explicit and systematic mechanism existed at the LIBRARY for linking what the librarians know to how this may support their customers and, more important, how the librarians' know-how and know-what could be systematically converted into corporate knowledge assets. The study also revealed new capabilities that are expected of librarians. Applying the proposed framework to the LIBRARY provided an opportunity to identify details of the knowledge activities involved in the transformation of customer knowledge that would not be possible otherwise. These detailed 
activities are available to other libraries in their operational, tactical, and strategic decision making.

\section{Limitations and Future Work}

The four major limitations of the current study are as follows: (i) The proposed theoretical model does not include factors related to the national and organizational culture. For example, what role does the (various levels of) culture play in, say, coding and classifying the data, information, and knowledge? How would culture affect data collection by outreach librarians? These are the subject of future studies. (ii) Related to the previous limitation, the current study has limited generalizability due to the nature of the case study approach used. By incorporating cases from various national and international academic libraries in future studies, the external validity of the current study will be enhanced greatly. (iii) Other library customers including undergraduates, postgraduates, and the general community were excluded from the current study. These roles will certainly affect the librarians' interactions with the proposed system as the main users of the proposed system. (iv) This study did not address the many ethical issues related to the implementation of such an interdepartmental system of data being collected from various organizations throughout the university and used by the library executives.

A future study is being planned to investigate the standard ways of anticipating knowledge for customers on the basis of the existing knowledge about and knowledge from customers. Can such a knowledge derivation process be automated for improved data quality? How can ICT facilitate or support the current resource-intensive face-to-face interviews for data collection? Work is already in progress for the design and development of an ontology-based CKMS that supports the initial phases of the decisionmaking processes of knowledge workers in the LIBRARY.

\section{Appendix}

\section{LIBRARY Customer Call Report}

Below are two customer call report samples: one for a customer from the Faculty of Arts and the other from the Faculty of Business. The abbreviations for the three major categories of customer knowledge, that is, knowledge for customer, knowledge about customer, and knowledge from customer, are shown by KFC, KAC, and KRC, respectively, underlined and within parentheses. 


\section{Sample 1: Call Report from Faculty of Arts}

Name: $<\mathrm{ABC}>\quad(\mathrm{KAC}) \quad$ ex\# 99999 (KAC)

Outreach Librarian: $<\mathrm{DEF}>\underline{(\mathrm{KFC})}$ Date of Visit: 5th March $2008 \underline{(\mathrm{KAC})}$

School: vvwvwvwvwv (KAC)

Faculty: FASS (KAC)

Teaching areas: $\underline{(\mathrm{KAC})}$

Undergraduate:

The Structure of Language

The Use of Language

Theoretical and Descriptive Linguistics

Generative Grammar

Linguistic Typology

Postgraduate:

Language and Mind

Bilingualism

Research active: YES (KAC)

Research areas: $\underline{(\mathrm{KAC})}$

Morphosyntactic theory (with particular reference to Generative Grammar), lexical semantics (with particular reference to Conceptual Semantics and Natural Semantic Metalanguage), and linguistic aspects of bilingualism.

Research Grants: (KAC)

ARC Large grant - Verbs and coverbs: . . .

RFCD Codes: (KAC)

Recent Publications: <as per link $>\underline{(\mathrm{KAC}) \&(\mathrm{KRC})}$

\section{PLAN SUMMARY}

What are the main content (collection) related issues that the Academic wishes to address?

1. Procedure for purchase requests. OK to send marked catalogue? (KRC)

2. Natural language and linguistic theory; Language. These journals are currently in printed issues; is the Library still subscribing? (KRC)

3. Trends in Linguistics [monograph series by Mouton] Library receives some volumes. Could MOSO be established? (potentially, a KRC)

How will this assist the academic? (KFC) \& (KRC)

When should this be delivered by? (KFC)

What is the Library offering to support this academic?

The Library subscribes to the major core journals in Linguistics in which the customer publishes. (KRC) \& (KFC)

What resources/websites/search engines/associations is the Academic using when locating content? 
The publishers, John Benjamins, Mouton de Greutyer are major publishers of interest (KFC) as well as a selection of linguistics journals which the Library holds (KFC). The customer actively participates in conferences and is a member of Australian Linguistic Society and Linguistic Society of America (KAC \& KRC);

Where do you and your School publish your research (list of journals, conferences, books, websites) and why? (KRC)

Would you like an advisory Research Performance Measurement service provided by the Library and measuring the performance of a researcher, a collection of selected articles, a journal or an institute? (KFC)

The customer is interested in this and supports it as a Library initiative (KRC). He and OL discussed possibilities of strategies which could involve individual academics or those researching in Linguistics as a discipline and he thinks more discussion at School level would be useful (KRC)

Brief History of Academic customer and Library relationship / use:

This customer was unaware of the services outlined by OL in the meeting. During the meeting, OL demonstrated the browse function on the LRD for identifying series and publishers. The customer was appreciative of this. He was especially interested in the RSS feed as he previously consulted the new book display. (KRC)

The customer was unaware of the subject guide for linguistics. He would like to look at it and will make suggestions/comments if he feels this is necessary. (KRC)

This meeting was curtailed by the arrival of a student who urgently required the customer's assistance $(\mathrm{KRC})$. He was very receptive to the new services and considers these excellent support by the Library (KRC). He is pleased to know that Outreach provides a specific member of Library staff with whom he can make initial contact (KRC).

\section{Actions}

OL will follow up the currency of the journals mentioned with Collection $\underline{(\mathrm{KFC})}$

OL will send links to services such as UNSWorks, Postgraduate ELISE and some other links discussed during the meeting. (KFC)

\section{Sample 2: Call Report from Faculty of Business}

Name: $\quad \angle A B C>(K A C)$

Position: Lecturer: (KAC) Ext: 99999 (KAC) Room: $x x x x x(\mathrm{KAC})$ Outreach Librarian: $<\mathrm{DEF}>\underline{(\mathrm{KFC})}$ Date of Visit: 28/5/2008 $\underline{(\mathrm{KAC})}$

School: Business Law \& Taxation (KAC)

Department: n/a (KAC)

Faculty: Australian School of Business (KAC)

Teaching areas: LEGT2721, $5511 \underline{(\mathrm{KAC})}$ 
Research active: (Yes/No) (KAC)

Research Area(s): $\underline{(\mathrm{KAC})}$

Franchising

Insolvency as it affects franchises

Property law

Unjust enrichment

Alternative dispute resolution

RFCD Codes: 390115, 390105 (KAC)

Recent Publications: $\underline{\text { (KAC) }}$

\section{PLAN SUMMARY}

How many times a month would you use the Library-USE means (website, physical building/collection/email/phone)?

Although this was not broached as an actual question, I was able to determine the customer used the Library to access databases and Online Repositories such as SSRN (KRC).

What are the main content (collection) related issues that the Academic wishes to address?

The customer uses the Library for online Databases including SSRN (KRC). She had questions pertaining to the use of SSRN (KAC). These primarily related to where best to upload Journal Articles, Working papers, Conference Papers and Chapters she had written, both in the past and more recently (KFC). We explained to the customer that although electronic repositories like SSRN were a valuable place to load her papers as they would be found when searching the WWW . . we demonstrated that when someone had a hit on her when searching they would have to be a subscriber to the actual repository (KFC). This led very well into informing her of the service provided by the library-UNSWorks (KAC) \& (KRC). She had not heard of it and was extremely happy and impressed with the Service $(\mathrm{KRC})$... amazed that everyone was not using it as it not only increased her visibility on the WWW but also saved a load of time compiling publication lists and such, which is a requirement as directed from her head of school in particular (KRC). Added UNSWorks to Jenny's Favourites and added Community of Scholars Universe and Funding to her 'MySpace' in SIRIUS.

Copyright issues were explained regarding pre and post refereed Journal Articles when posting papers and such onto UNSWorks and other such repositories (KFC). Added Sherpa Romeo to the customer's Favourites (KFC).

Primarily the customer would like to see if Collections Development Team (CDT) can look into more relevant up to date books related to her field ... Economics and the Law (especially relating to Franchise if possible) (KAC) \& (KFC), and also what content we have pertaining to Em- 
pirical Research and the Law (KAC). I will inform Collections of this and see if they are able to source other more up to date monographs etc (KFC). I will also discuss with the Faculty of Law Outreach librarian to determine if the Law Library may have content that I can suggest Jenny investigates (KFC).

We discussed the New Library Research Start-up Fund. Given the nature of the customer's research we determined she would certainly qualify for inclusion given no one was looking into the Economic/Legal issues around Franchise Failure (KFC). She will email me, outlining her field of research and a 'wish list' for me to pass onto Collections. As she is rather busy between now and the beginning of July we agreed that I would contact her early in July as a reminder to do this (KFC).

She had a small issue with Factiva (KAC) which I was able to show her $\underline{(\mathrm{KFC})}$ and she was very happy with this (KRC). I showed her how to set up database alerts within SIRUIS. When we attempted to set up alerts with in Factiva this led to a discussion on RSS Feeds, something she is keen to know more about (KRC). Due to time constraints I talked with her and will talk her through setting up RSS feeds over the phone at a time convenient to her.

\section{How will this assist the academic?}

Building up the collection in her research \& teaching areas will assist the academic's endeavours (KRC).

When should this be delivered by?

Over the forthcoming months weaknesses in the collection will be referred to the CDT for appraisal. (KFC)

What is the Library offering to support this academic? $\underline{(\mathrm{KRC})}$

SIRUIS

UNSWorks

E-journals

SSRN

What resources is the Academic using when locating content? (KRC)

Where do you and your School publish your research (list of journals, conferences, books, web sites) and why?

Currently using SSRN Repository (KRC),

Explained UNSWorks as detailed above (KFC).

Would you like a Publishing Activity Consultancy Service provided by the Library?

Not discussed

Brief History of Academic and Library relationship / use:

This is the second meeting "aaaaaa" has had with an Outreach Librarian [the "aaaaaa" is the hidden identity of the interviewee]. She was able to disclose this was the most enlightening meeting she had had and was very 
happy with the meeting and impressed with the support and services provided by the Library (KRC).

\section{Actions:}

Email the customer the EndNote Training via the web (KFC)

Contact "xxx" (Head of School) and "yyy" with a view to their encouraging all with in the School to use UNSWorks, perhaps arrange a presentation (KFC).

Discuss with them the possibility of my attending School Meetings (KFC), Assist the customer with setting up RSS feeds (KFC).

Speak with Collections re Economics \& the Law content within the Library as well as investigate if the Collection has any content relating to Empirical Research and the Law $(\mathrm{KFC})$

Follow up with the customer in early July regarding the New Library Research Start-up Fund (KFC)

\section{REFERENCES}

1. Smith, Reid G., and Farquhar, Adam. "The Road Ahead for the Knowledge Management: An AI Perspective." AI Magazine 21, no. 4 (2000): 17-40.

2. Daneshgar, F., and Parirokh, M. "A Knowledge-Base Schema for Organisational Learning in Academic Libraries." Journal of Knowledge Management Research and Practice 5, no. 1 (2007): 22-33.

3. Association of Research Libraries. "LibQUAL+: Charting Library Service Quality." ARL, Washington, DC, 2011. http://www.libqual.org/about/about_lq/general_info.

4. Turban, E.; Leidner, D.; McLean, E.; and Wetherebe, J. Information Technology for Management: Transforming Business into Digital Economy. 3rd ed. New York: Wiley, 2008.

5. Bose, Ranjit, and Sugumaran, Vijaya. "Application of Knowledge Management Technology in Customer Relationship Management." Knowledee and Process Management 10, no. 1 (2003): 3-17.

6. Davenport, T. H.; Harris, J. G.; and Kohli, A. K. "How Do They Know Their Customers So Well?" M.I.T. Sloan Management Review 42, no. 2 (2002): 63-73.

7. McCombs, G. M. Access Services: The Convergence of Reference and Technical Services. New York: Haworth, 1992.

8. Parirokh, M.; Daneshgar, F.; and Fattahi, R. "Identifying Knowledge-Sharing Requirements in Academic Libraries." Library Review 57, no. 2 (2008): 107-22.

9. Möller, K. "Role of Competences in Creating Customer Value: A Value-Creation Logic Approach." Industrial Marketing Management 38, no. 8 (2006): 913-24.

10. Yakhlef, A. "Immobility of Tacit Knowledge and the Displacement of the Locus of Innovation." European Journal of Innovation Management 8, no. 2 (2005): 227-39.

11. Gibbert, T. M., Leibold, M.; and Probst, G. "Five Styles of Customer Knowledge Management, and How Smart Companies Put Them into Action." European Management Journal 20, no. 5 (2002): 459-69.

12. Hoe, S. L. "Benefitting from Customers and Competitor Knowledge." Learning Organization 15, no. 3 (2008): 240-50.

13. Dalkir, Kimiz. Knowledge Management in Theory and Practice. London: Elsevier, 2005. 
14. Bueren, A.; Schierholz, R.; Kolbe, L.; and Brenner, W. "Customer Knowledge Management: Improving Performance of Customer Relationship Management with Knowledge Management." In System Sciences, 2004: Proceedings of the 37th Annual Hawaii International Conference on Systems Science, edited by Ralph H. Sprague. Los Alamitos, CA: Institute of Electrical and Electronics Engineers Computer Society, 2004.

15. Su, C.; Chen, Y.; and Sah, D. Y. "Linking Innovative Product Development with Customer Knowledge: A Data-Mining Approach.” Technovation 26, no. 7 (2006): 784-95.

16. Alavi, M., and Leidner, D. E. "Knowledge Management Systems: Issues, Challenges and Benefits." In [17].

17. Barnes, S. Knowledge Management Systems: Theory and Practice. London: Thomson Learning, 2002.

18. Jashapara, Ashuk. Knowledge Management: An Integrated Approach. London: PrenticeHall, 2004.

19. Gebert, Henning; Geib, Malte; Kolbe, Lutz; and Brenner, Walter. "Towards Customer Knowledge Management: Integrating Customer Relationship Management and Knowledge Management Concepts.” In ICEB 2002: Conference Proceedings, pp. 296-98. Taipei: National Chiao Tung University, 2002.

20. Daneshgar, F., and Bosanquet, L. "Organizing Customer Knowledge in Academic Libraries." Electronic Journal of Knowledge Management 8, no. 1 (2010): 31-32.

21. Olive, A. Conceptual Modeling of Information Systems. Berlin: Springer, 2007.

22. Gebert, Henning; Geib, Malte; and Kolbe, Lutz. "Knowledge-Enabled Customer Relationship Management: Integrating Customer Relationship Management and Knowledge Management Concepts." Iournal of Knowledge Management 7, no. 5 (2003): 10723.

23. Levine, John, and Moreland, Richard. "Progress in Small Group Research." Annual Review of Psychology 41 (1990): 585-634.

24. Strauss, Anselm, and Corbin, Juliet M. Basics of Qualitative Research: Grounded Theory Procedures and Techniques. London: Saga, 1998.

25. Lincoln, Y. S., and Guba, E. Naturalistic Inquiry. Beverly Hills, CA: Saga, 1985.

26. Lindland, O.; Sindre, G.; and Solvberg, G. "Understanding Quality in Conceptual Modeling." IEEE Software 11, no. 2 (1994): 42-49. 